\title{
ENTERIC PARASITES WITH ZOONOTIC IMPORTANCE IN JACKAL (CANIS AUREUS LINNAEUS,1758)
}

\author{
RAIHANUL JANNAT, HAMIDA KHANUM", RIMI FARHANA ZAMAN, SHARMIN MUSA, MANDIRA MUKUTMONI \\ and FAHMIDA SARKER
}

Department of Zoology, University of Dhaka, Dhaka (Bangladesh)

\begin{abstract}
The investigation was conducted to determine the prevalence of gastrointestinal parasites in jackal of Barisal, Bangladesh. The study period was May,2017-April,2018. Out of 30 jackal, 25 jackal (83.33\%) were infected by different species of parasites. The association of age, sex of the hosts and season were also observed. Fecal analyses were screened via using Formol-Ether concentration technique for parasite ova, cysts, oocysts and larvae. During the study period, total thirteen species of parasites were identified. Among them Toxocara canis had highest prevalence rate $(83.33 \%)$ and higher prevalence followed by Isospora spp. (76.67\%), Ancylostoma spp. (76.67\%), Echinococcus granulosus $(53.33 \%)$ and Mesocestoides lineatus $(53.33 \%)$. The prevalence of parasites in jackal was highest in $4-5$ years age group $(85.71 \%)$ and $8-9$ years age group $(85.71 \%)$ and was statistically significant $(p<0.05)$. In all years age groups, Toxocara canis had highest prevalence $(85.71 \%)$. Females $(100 \%)$ had higher infection than the males $(76.92 \%)$. Statistically it was also significant $(p<0.05)$. The parasites which had higher prevalence rate in females were Toxocara canis (100\%) and Isospora sp. (82.35). Ancylostoma spp. (76.92\%), Toxocara canis and Isospora sp. (69.23\%) had higher prevalence rate in males. Prevalence of parasite species in jackal was highest in summer $(\mathbf{1 0 0 \% )}$ ) and in winter $(100 \%)$ and was statistically significant $(p<0.05)$. From the above result, it could be stated that jackal act as zoonotic agent which is a threat for human health.
\end{abstract}

Key words : Jackals, Gastrointestinal parasites, Zoonotic importance, Prevalence.

\section{INTRODUCTION}

Parasites affecting both domestic and wild carnivores may circulate between and among sympatric populations of animals thus facilitating potential spill over the infections to humans (Polley,2005). In fact, the first source of human infection with zoonotic agents (virus, protozoa, bacteria and fungi) are wild and domestic carnivores. The resilience of ecosystems is being challenged by the thinning boundaries between domestic and wild animals, ultimately resulting in a redistribution of infective agents (Thompson et al.,2010; Colwell et al.,2011 and Tompkins et al.,2015). Under these changed circumstances, there is not only concern for preserving animals and the environment, but them likely to become a threat to human health, especially considering their effects on the epidemiology of some infectious diseases. The burden of contagious diseases and parasites are affected by many factors, including the time length of animals' removal from the wild, degree of adjustment, captivity and quality of the captive management etc.

Wild animal harbor numerous parasites in their free living stage, but seldom lead to harmful infection unless stressed (Lim et al.,2008). Jackals harbor many parasites of zoonotic importance, which are harmful for human health. The population of wild canids can endure serious epizooty, caused by that parasite species in pet dogs. Foxes and jackal have a great epizootical-epidemiological importance, considering that some agents of vector borne diseases parasite in them, from which the most important are i.e. Leishmaniosis, Babesiosis, Boreliosis, Dirofilariosis, Bartonellosis and Hepatozoonosis (Ilic et al.,2012).
Numerous parasites are recognized from golden jackal across their geographic array and definite groups can be spread during their expansion, increasing the risk of crossinfection with other carnivores or even humans (Gherman and Mihalka,2017). The flow of parasites from wildlife to domestic carnivores and vice versa mostly depends on the specific ecological variants which characterize each given area. For example, hunting practices, as well as human encroachment in wildlife habitats may facilitate the spill-over of parasitic infections from domestic canids and felids to wild populations. Similarly, the establishment of wildlife reservoirs may determine a subsequent spill-back of the same parasites to populations of domestic animals, ultimately prolonging the life cycles of parasites (Otranto et al.,2015).

A number of parasites including T.hydatigena, D.immitis, D.nolleri, A.caninum, T.canis, common parasites between jackal and foxes whereas, Echinococcus granulosus, Macroacanthorhynchus hirudinaceus, Dermacentor sp. parasitized jackal and Ixodes ricinus, Haemaphysalis sp. parasitized foxes. Anumber of diseases already reported in foxes and jackal, heart worm infestation (Mulley and Starr,1984), intestinal nematodiasis (Malczewski,1962), leishmaniasis (Khan et al.,2012), tuberculosis (TB), infectious canine hepatitis (ICH), rabies and toxoplasmosis (Smith et al.,2003).

Sometimes the jackals provoke damages in protected areas; in other situation it attacks livestock, or it can be found on hunting areas eating small game species (Lapini and Banea,2013). There rises a chance of entrance in to human habitation and thus the contaminated feces of the jackal may facilitate dispersion of parasite eggs which is termed as Zooanthroponosis; a type of zoonotic disease that can be 
passed between animals and humans. A major role in the epidemiology of zoonosis is played by wild and domestic animals (Shaikh and Huq,1984). The transmission of zoonotic agents could be through indirect contact with animal secretions and excretions, infected water and food, fecal samples and through direct contact with the animal. Ecosystems of a particular area is also an important factor for the distribution of zoonotic parasites. It includes defend biosensors which are composed of mutually connected communities combined with the local vegetable and microbial world (Slifko et al., 2000). Understanding the epidemiology of zoonoses parasitic infections is important to minimize risk of human infection.

The meso-carnivores; such as jackal, or the omnivores animals are always open to parasites and thus are constantly being strike in chain reaction mode. Carnivore host a wide range of internal and external parasites, including protozoans, nematodes, trematodes, cestodes, fleas, lice and ticks (Roberts and Janovy,2000). In wild conditions, animal have some natural resistance against parasitic diseases and there is a state of equilibrium between the parasite and the host and it seldom lead to harmful infection unless stressed (Gaur et al.,1979). Golden jackal play an important scavenging role by eating garbage and animal carrion around towns and villages. They benefit agriculture by preventing increases in the number of rodents and lagomorphs. They are sometimes hunted for their fur. Golden jackal that are hand-raised can be tamed and kept in houses.

\section{MATERIAL AND METHODS}

The present investigation was aimed to determine the prevalence of intestinal parasites in jackal of Barisal among the aged between 4-9 years during May,2017-April,2018.The fecal sample were collected randomly from the fields. Prior to collection, all possible hygienic measures like wearing apron, hand gloves and shoes were taken to avoid contamination. A total of 30 samples were collected. Samples were collected according to three different age groups. These were $1.4-5$ years age group, 2.6-7 years age group and 3. 8-9 years age group.

The fecal samples of jackal were collected randomly from the fields. Prior to collection, all possible hygienic mea- sures like wearing apron, hand gloves and shoes were taken to avoid contamination. A total of 30 samples were collected. Every sample was kept in a plastic pot, cautiously silted and correctly numbered. The samples were stored in $10 \%$ formalin. The tied labeled and numbered pots containing fecal samples with all the necessary information were brought to the laboratory and explored.

Detection of parasites egg and ova, Formol Ether concentration technique was applied. Both protozoan and helminth ova and eggs present in fecal samples can be observed by this technique and also be examined by this technique. The movement of parasite's eggs was not seen in a formol ether concentration technique (Cheesbourgh,1987) because formalin kills the living organisms. Finally the ova and cysts were observed and identified according to following the descriptions by Chatterjee (2014), Soulsby (1982), Cheng (1986) and Schmidt \& Roberts (1989). Significant test was done be standard software (SPSS, version 13.0, SPSS Inc., Chicago,III) and value of $\mathrm{p}<0.05$ were considered significant.

\section{RESULTS AND DISCUSSION}

In the present work, 30 jackal were infected with different parasites which had different degree of prevalence. Significant prevalence was found in T.canis $(83.33 \%)$, A.spp. (76.67\%), Isospora (76.67\%), E.granulosus (53.33\%), M.lineatus (53.33\%), E.histolytica (43.33\%) and T.vulpis $(43.33 \%)$. Some researchers found different prevalence (Table.1). Ilic et al. (2016) found 6.66\% in Isospora spp., $23.33 \%$ in T.canis, $33.33 \%$ in Ancylostomatidae, $11.66 \%$ in T.vulpis, $3.33 \%$ in P.truncatum and $1.66 \%$ in M.yokogawai (Table.1).

Takacs et al. (2014) found 5\% Toxoplasma type oocyst, $20 \%$ in M.lineatus, $15 \%$ in C.canis, $10 \%$ in E.granulosus, $5 \%$ in D.caninum, $15 \%$ in T.hydatigena, $40 \%$ in T.crassiceps, $20 \%$ in T.pisiformis, $10 \%$ in T.vulpis, $40 \%$ in A.caninum, $5 \%$ in C.aerophila, $45 \%$ in C.plica, $20 \%$ in T.canis and $15 \%$ in T.leonina. Borecka et al. (2013) found 31 parasite eggs $(68.9 \%)$. The most prevalent was Trichuris vulpis $(64.4 \%)$, along with T.canis $(11.1 \%)$, Ancylostomal Uncinaria (8.9\%) and taeniids (2.2\%). Rataj et al. (2013) found U.stenocephala (58.9\%), Toxocara canis $(38.3 \%)$ and

Table. 1 Prevalence and intensity of different parasites species in jackal.

\begin{tabular}{|c|c|c|c|c|c|}
\hline Name of the parasites & Total no. of host & No. of host infected & Prevalence in hosts $(\%)$ & EPG or CPG & Intensity \pm SD \\
\hline Isospora $\mathrm{sp.}$ & 30 & 23 & 76.67 & 742 & $32.26 \pm 26.31$ \\
\hline Entamoeba histolytica & 30 & 13 & 43.33 & 64 & $4.92 \pm 3.58$ \\
\hline Taenia $\mathrm{sp}$ & 30 & 11 & 36.67 & 42 & $3.82 \pm 2.84$ \\
\hline Echinococcus granulosus & 30 & 16 & 53.33 & 84 & $5.25 \pm 4.38$ \\
\hline Mesocestoides lineatus & 30 & 16 & 53.33 & 76 & $4.75 \pm 4.77$ \\
\hline Moniezia expansa & 30 & 3 & 10 & 3 & $1 \pm 0.31$ \\
\hline Diphyllobothrium latum & 30 & 10 & 33.33 & 12 & $1.2 \pm 0.62$ \\
\hline Opisthorchis sp. & 30 & 7 & 23.33 & 7 & $1 \pm 0.43$ \\
\hline Toxocara canis & 30 & 25 & 83.33 & 303 & $12.12 \pm 8.01$ \\
\hline Ancylostoma sp. & 30 & 23 & 76.67 & 164 & $7.13 \pm 5.49$ \\
\hline Capillaria sp. & 30 & 07 & 23.33 & 28 & $4 \pm 2.36$ \\
\hline Trichuris vulpis & 30 & 13 & 43.33 & 60 & $4.62 \pm 3.25$ \\
\hline Gnathostoma spinigerum & 30 & 06 & 20 & 29 & $4.83 \pm 2.40$ \\
\hline
\end{tabular}


M.patens (30.6\%). Other nematodes were P.saffinis (4.2\%), Capillaria sp. (2.8\%), C.vulpis (2.8\%), T.leonina (2.5\%), T.vulpis (0.7\%) and Physaloptera spp. (0.2\%). Mesocestoides spp. (27.6\%) and T.crassiceps $(22.2 \%)$ were the most prevalent cestodes, followed by T.polyacantha (6.5\%), H.nana (2.1\%), T.pisiformis $(2.1 \%)$ and D.caninum (1.4\%). Rataj et al. (2013) also stated four trematode species : R.donicum (1.6\%), H.heterophyes (1.1\%), M.yokogawai (1.1\%), P.appendiculatum $(0.4 \%)$ and two protozoan species : oocysts of Sarcocystis (2.8\%) and Isospora (0.4\%).

Parasites community in jackals in relation to their sex : The sex of host might have an impact on parasites infection. That's why in the present study, sex of jackals was taken as a factor. A total of 13 males and 17 females were examined. Among them 10 males (76.92\%) and 17 females (100\%) were infected. Statically it was also significant $(\mathrm{P}<0.05)$. So, females had higher prevalence than the males (Table.2). But the intensity was higher in male (77.6 \pm 39.58$)$ than in female (49.18 \pm 18.52$)$ (Table.2)

Prevalence of different parasite species in jackals in relation to their sex : The highest prevalence rate was found in females than in males. Parasites which had higher prevalence rate in females were Toxocara canis (100\%) and Isospora sp. $(82.35 \%)$ (Fig.1). Parasites which had higher prevalence rate in males were Ancylostoma spp. (76.92\%), Toxocara canis (69.23) and Isospora spp. (69.23\%) (Fig.2). Isospora spp. had highest intensity in male $(42.22 \pm 35.62)$ and female $(25.85 \pm$ 16.55) (Figs.1\&2). The highest prevalence rate was found in females than in males.

Prevalence of parasite species in different age-groups of jackal : Prevalence of parasites in jackal was highest in 4-5 years age group $(85.71 \%)$ and $8-9$ years age group $(85.71 \%)$ followed by 6-7 years age group (77.78\%) (Table.3). The prevalence of 4-5 years age group and 8-9 years age group was statistically significant $(\mathrm{p}<0.05)$. The intensity of parasites was higher in 6-7 years age group (96.42 \pm 39.28$)$ followed by $8-9$ years age group (60 \pm 24.54$)$ and $4-5$ years age group (52.25 $19.47)$. In $4-5$ years age group, T.canis $(85.71 \%)$ had highest prevalence and Isospora spp. had highest intensity (22.27士 13.81). Other parasites which had higher prevalence were Isospora spp. (78.57), Ancylostoma spp. (78.57) and M.lineatus (64.29) (Fig.2). Parasites which had high intensity were T.canis $(10.75 \pm 7.44)$ and M.lineatus $(6.44 \pm 6.05)$ (Fig.1).

In 6-7 year age group, T.canis had highest prevalence rate $(88.89 \%)$ and Isospora $\mathrm{sp}$. had highest intensity rate (48.71 \pm 37.79$)$. Some other parasites showed high infestation Isospora sp. (77.78\%), E.granulosus (77.78\%), E. histolytica (66.67\%) and Ancylostoma sp. (66.67\%). Parasites which had high intensity were T.canis (11.88 \pm 8.57$)$, E.granulosus

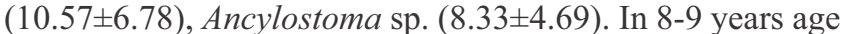
group, Toxocara canis had highest prevalence rate $(85.71 \%)$ and Isospora sp. had highest intensity (31.2 \pm 25.26$)$.

Others parasites which showed higher infestation rate were Isospora sp. (71.43\%), Ancylostoma sp. (71.43\%), E.granulosus (57.14\%) and M.lineatus (57.14\%). Other parasites which had higher intensity were T.canis $(13.17 \pm 9.38)$,

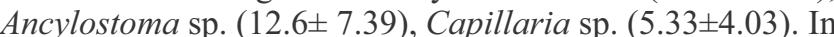
age related study, sufficient results were not found related to jackal. That's why present study has been compared with previous work of fox. Richards et al. (1995) found no significant differences between the number of juvenile and adult foxes from Bristol harbouring U.astenocephala, T.pisiformis, T.hydatigena, D.caninum, B.recurva or C.lingua (Figs.3\&4).

Seasonal variation of prevalence and intensity of different parasite species in jackal : Prevalence of parasite species in jackal was highest in summer $(100 \%)$ followed by in winter $(100 \%)$ and monsoon $(70 \%)$. The prevalence of parasites in summer, monsoon and winter was statistically significant $(p<0.05)$. The intensity of parasites was higher during summer (142.04 \pm 34.34$)$ followed by in winter $(104.15 \pm 24.22)$ and monsoon (69.41 19.06$)$ (Table.4).

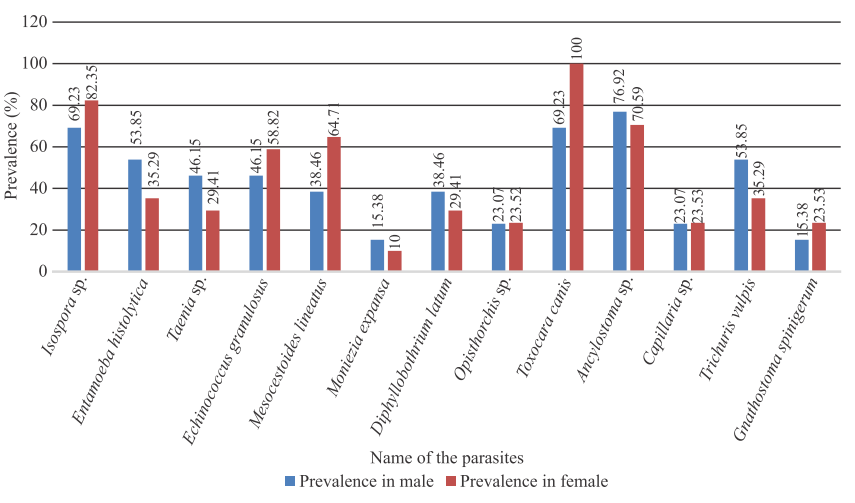

Fig. 1 Prevalence of different parasites species in jackal in relation to sex.

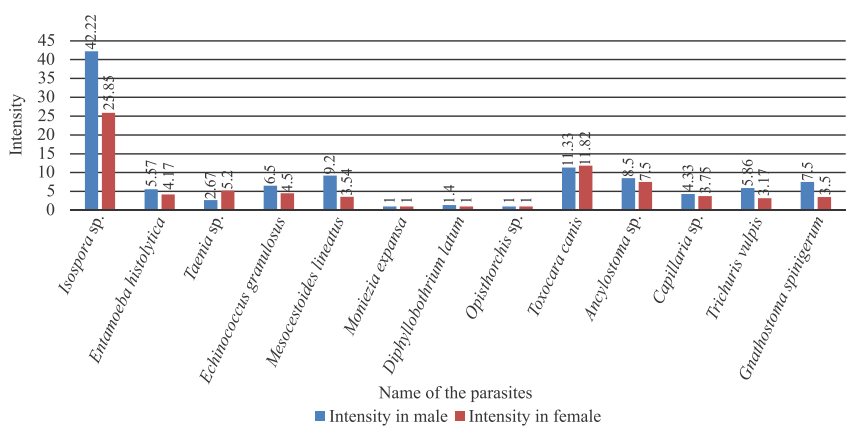

Fig. 2 Intensity of different parasites species in jackal in relation to sex.

Table. 2 Prevalence and intensity of different parasites species in jackal in relation ton sex.

\begin{tabular}{|c|c|c|c|c|c|c|}
\hline Sex of hosts & Total no. of host & Total No. of host infected & Prevalence in hosts (\%) & EPG or CPG & Intensity \pm SD & P value \\
\hline Male & 13 & 10 & 76.92 & 788 & $78.8 \pm 39.84$ & 0.05 \\
\hline Female & 17 & 17 & 100 & 836 & $49.18 \pm 17.38$ & 0.05 \\
\hline
\end{tabular}


(A) Prevalence of different species of parasites in jackal in summer (March-June) : During summer, prevalence of parasites was found higher in jackal. Total eleven species of parasites were found. Among them highest prevalence rate $(100 \%)$ was found in Isospora sp. The highest intensity (45.5 \pm 32.41$)$ was also found in Isospora spp. Prevalence was also found higher in T.canis and Ancylostoma sp. which was, $90 \% \& 80 \%$, respectively M.expansa and G.spinigerum was not found in summer.

(B) Prevalence of different species of parasites in jackal in monsoon (July-October) : In monsoon, prevalence and intensity of different parasites were not so high. Total thirteen

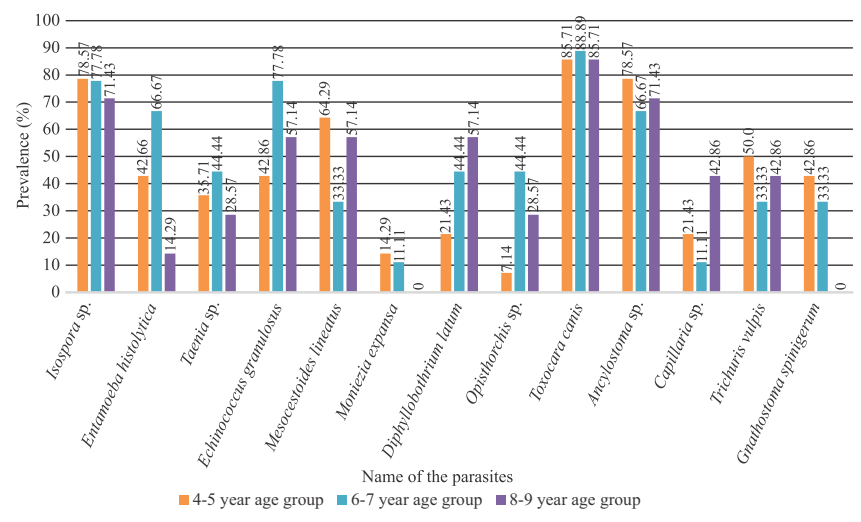

Fig. 3 Prevalence of different parasites species in jackal in relation to age group.

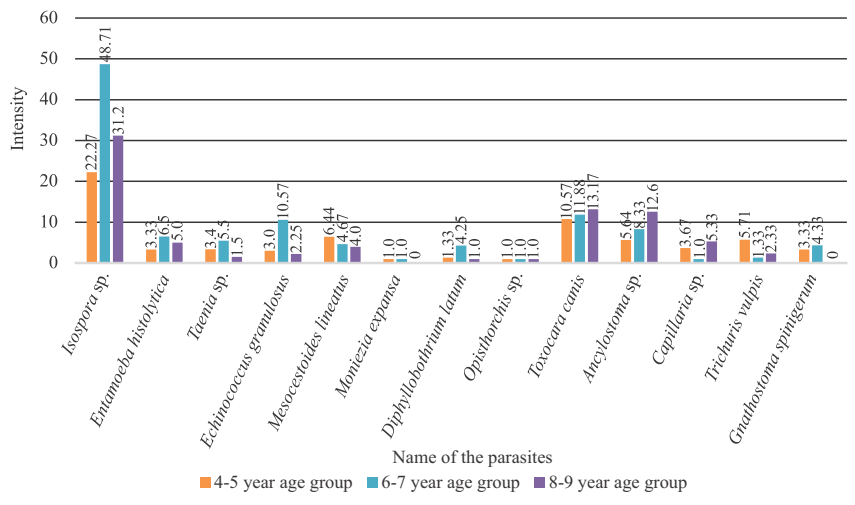

Fig. 4 Intensity of different parasites species in jackal in relation to age group. species of parasites were found (Table.12). Among them Toxocara canis and Ancylostoma sp. had highest prevalence rate $(70 \%)$. Isospora sp. had highest intensity $(16.4 \pm 10.78)$ and its prevalence was $50 \%$ (Fig.5).

(C) Prevalence of different parasite species in jackal in winter (November-February) : During winter, prevalence and intensity of parasites were very high. Total thirteen species of parasites were found (Table.13). Toxocara canis $(100 \%)$ and Isospora sp. (80\%) had highest prevalence rate. And Mesocestoides lineatus (70\%) and Ancylostoma sp. $(70 \%)$ had second highest prevalence rate. Isospora sp. had highest intensity rate $25.62 \pm 16.13$ (Figs.5\&6).

Prevalence of parasite species in jackal was highest in summer $(100 \%)$ followed by in winter $(100 \%)$ and monsoon $(70 \%)$. The prevalence of parasites in summer, monsoon and winter was statistically significant $(p<0.05)$. The intensity of parasites was higher during summer (142.04 \pm 3.34$)$ followed by in winter $(104.15 \pm 24.22)$ and monsoon $(69.41 \pm 19.06)$ (Figs.5\&6).

During summer, prevalence of parasites was found higher in jackal. Total eleven species of parasites were found. Among them highest prevalence rate $(100 \%)$ was found in Isospora $\mathrm{sp}$. The highest intensity $(45.5 \pm 32.41)$ was also found in Isospora sp. Prevalence was also found higher in T.canis and Ancylostoma sp. which was, $90 \% \& 80 \%$, respectively, M.expansa and G.spinigerum was not found in summer (Figs.5\&6). During winter, prevalence and intensity of parasites were very high. Total thirteen species of parasites were found. T.canis $(100 \%)$ and Isospora sp. $(80 \%)$ had highest prevalence rate; M.lineatus (70\%) and Ancylostoma sp. $(70 \%)$ had second highest prevalence rate. Isospora sp. had highest intensity rate $25.62 \pm 16.13$ (Figs. $5 \& 6$ ).

Due to their free range, wild carnivores represent an important source of eggs of T.vulpis, which contaminate the environment and expose domestic carnivores to the possibility of infection (Kirkova et al.,2006). This nematode was detected in foxes in other countries in Southeast Europe (Di Cerbo et al.,2008; Borecka et al.,2013 and Rataj et al.,2013) and it has been proven that it can cause visceral larva migrans (VLM) in humans (Masuda et al.,1987 and Márquez-Navarro et al.,2012). Due to zoonosis, the potential of this species and the role of dogs, foxes and jack wolf as the source of infection,

Table. 3 Prevalence and intensity of parasites in relation to age of jackal.

\begin{tabular}{|c|c|c|c|c|c|c|}
\hline Age of hosts & Total no. of host & No. of host infected & Prevalence in hosts (\%) & EPG or CPG & Intensity \pm SD & P value \\
\hline 4-5 years & 14 & 12 & 85.71 & 627 & $52.25 \pm 19.47$ & 0.03 \\
\hline $6-7$ years & 9 & 7 & 77.78 & 675 & $96.42 \pm 39.28$ & 0.07 \\
\hline $8-9$ years & 7 & 6 & 85.71 & 360 & $60.00 \pm 24.54$ & 0.0001 \\
\hline
\end{tabular}

Table. 4 Seasonal variation of prevalence and intensity of different species of parasites in jackal.

\begin{tabular}{|c|c|c|c|c|c|c|}
\hline Seasons & Total no. of host & No. of host infected & Prevalence in hosts (\%) & EPG or CPG & Intensity $\pm \mathrm{SD}$ & P value \\
\hline Summer & 10 & 10 & $100 \%$ & 705 & $70.5 \pm 34.10$ & 0.001 \\
\hline Monsoon & 10 & 7 & $70 \%$ & 360 & $51.43 \pm 18.99$ & 0.005 \\
\hline Winter & 10 & 10 & $100 \%$ & 534 & $35.4 \pm 25.17$ & 0.0002 \\
\hline
\end{tabular}




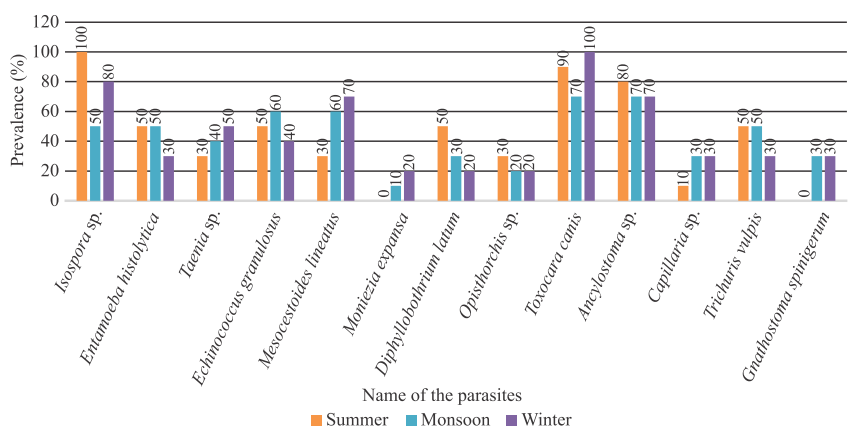

Fig. 5 Prevalence of different parasites species in jackal in relation to seasons.

the most important is to set accurate diagnosis to prevent further infection or reinfection (Ilic et al.,2016).

Jackals share their habitats with domestic dogs and a wide variety of wild carnivores across their distribution range and the high similarity with canine parasites (Taylor et al., 2007 and Adeniyi et al.,2015). The vast majority of parasites recorded in golden jackal are shared with domestic dogs or even domestic cats. Other parasites of jackal can use a wide variety of other domestic species, including livestock, as intermediate hosts (Gherman and Mihalca,2017). In our country, Diphyllobothrium latum, Heterophyes sp., Opisthorchis sp., Ancylostoma spp., Gnathostoma spp., Toxocara canis, Toxocara cati, these parasites were declared as zoonotic parasites by Shaikh and Huq (1984). Due to their free range, wild carnivores represent an important source of eggs of Trichuris vulpis, which contaminate the environment and expose domestic carnivores to the possibility of infection (Kirkova et al.,2006).

Zoonosis with wildlife reservoirs represent a major public health problem affecting all continents, therefore the importance and recognition of wildlife as a reservoir is increasing (Meshgi et al.,2009). Red foxes and jackals can serve as a potential source of infection for humans and domestic animals because of their free roaming in residential areas. Several studies have been carried out on the endo parasites of stray dogs and wild carnivores in order to show their zoonotic importance (Kruse et al.,2004; Vervaeke et al.,2005 and Dalimi et al.,2006). Parasitic zoonosis of wild carnivores are becoming a more actual public health problem around the

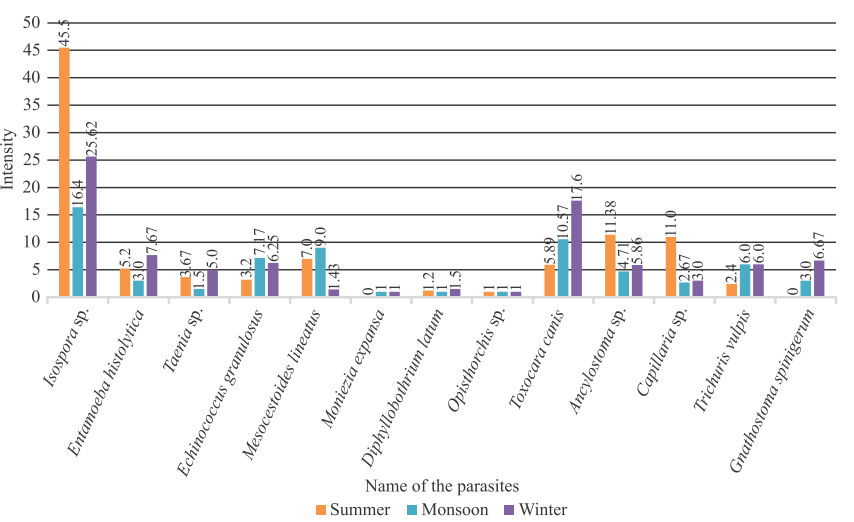

Fig. 6 Intensity of different parasites species in jackal in relation to seasons.

world, which is why the importance and role of these species of carnivores as reservoirs of infection, only further increases (Ilic et al.,2016). In order to predict the extent of certain zoonotic diseases in certain parts of Barisal in Bangladesh, jackals are the source for infection and it is necessary to control the parasites of these carnivores.

Populations of a specific group are identified as having a higher risk of acquiring parasitic zoonosis than others. These higher risk groups include small children, pregnant woman and the immuno compromised. These groups pose this higher risk partly because of behavioral characteristics and partly because of immunological reasons. For an example Toxocara sp. can cause toxocariasis which can damage retina and decreased vision. The feces also have hookworms that cause cutaneous larva migrants in humans.

Parasitic zoonosis of wild carnivores are becoming a more actual public health problem around the world, which is why the importance and role of these species of carnivores as reservoirs of infection, only further increases (Ilic et al., 2016). Parasite species lives in jackal are zoonotically significant and harmful to human health. Jackals hold lots of infective stages of disease causative agents transmissible to human. As jackal perform as zoonotic agents, it is necessary to take adequate proper steps to eradicate this kind of contamination. By following proper prevention methods, these animals can be an integral part of our life. Cleanliness is the best way to prevent zoonotic infection of jackal.

\section{REFERENCES}

Adeniyi, I. C.; Morenikeji, O. A. and Emikpe, B . O. (2015). The prevalence of gastrointestinal parasites of carnivores in university zoological gardens in South West. Journal of Veterinary Medicine and Animal Health, 7(4) : 135-39.

Blaga, R.; Gherman, C.: Seucom, D.; Cozma, V. and Boireau, P. (2008). First identification of Trichinella sp. in golden jackal (Canis aureus) in Romania. Journal of Wildlife Diseases, 44 : 457-459.

Borecka, A.; Gawor, J. and Zieba, F. (2013). A survey of intestinal helminths in wild carnivores from the Tatra National Park, Southern Poland. Annals of Parasitology, 59: 169-172.

Chatterjee, K. D. (2009). Parasitology - Protozoa and Helminthology: $13^{\text {th }}$ edn. CBS Publishers, p. 298

Cheesbrough, M. (1987). Medical Laboratory Manual for Tropical Countries : $2^{\text {nd }}$ edn. Tropical Health Technology, London, Boston, Blackworths, $13: 570$. 
Cheng, T. C. (1986). General Parasitology $: 2^{\text {nd }}$ edn. Academic Press College Division, Orlando, p. 827.

Dalimi, A.; Sattari, A. and Motamedi, G. H. (2006). A study on intestinal helminthes of dogs, foxes and jackals in the Western part of Iran. Veterinary Parasitology, $142: 129-133$.

Di Cerbo, R. A.; Manfredi, T. M.; Bregoli, M.; Ferro Milone, N. and Cova, M. (2008). Wild carnivores as source of zoonotic helminths in North-Eastern Italy. Helminthologia, 45(1) : 13-19.

Gaur, S. N. S.; Sethi, M. S.; Tewari, H. C. and Prakash, O. (1979). A note on the prevalence of helminth parasites in wild and zoo animals in Uttar Pradesh. Indian Journal of Animal Sciences, 46 : 159-161.

Gherman, C. M. and Mihalca, A. D. (2017). A synoptic overview of golden jackal parasites reveals high diversity of species. Parasites and Vectors, $\mathbf{1 0}: 419$.

Harkiral, S.; Jyoti, H. M.; Singh, N. K. and Rath, S. S. (2012). Prevalence of canine parasitic infections in and around Ludhiana. Journal of Veterinary Parasitology, 25(2): 179-180.

Ilic, T.; Savic, S. and Dimitrijevic, S. (2012). Epizotio-epidemiological importance of parasitic infection in wild canides. In : Serbian. Veterinarski Glasnik, $66: 299-309$.

Ilic, T; Becskei, Z.; Petrovic, T.; Polacek, V.; Ristic, B.; Milic, S.; Stepanovic, P.; Radisavljevic, K. and Dimitrijevic, S. (2016). Endoparasitic fauna of red foxes (Vulpes vulpes) and golden jackal (Canis aureus) in Serbia. Acta Parasitologica, 61(2) : 389-396.

Javaregowda, K. A. (2016). Studies on prevalence of endo-parasitic infection in wild carnivores maintained under captive state. Journal of Parasitic Diseases, 40(4) : 1155-1158.

Kirkova, Z.; Georgieva, D. and Raychev, E. (2006). Study on the prevalence of Trichurosis in different categories of dogs and wild carnivores. Bulgarian Journal of Veterinary Medicine, $9: 141-147$.

Kruse, H.; Kirkemo, A. and Handeland, K.(2004). Wildlife as a source of zoonotic infections. Emerging Infectious Diseases, 10 : $2067-2072$.

Lahmar, S.; Boufana, B.; Ben Boubaker, S. and Landolsi, F. (2014). Intestinal helminths of golden jackal and red foxes from Tunisia. Veterinary Parasitology, 204(3-4): 297-303.

Lapini, L. and Banea, C. O. (2014). Life-history traits, anthropogenic expansion and conservation status of the GJ in Europe $1^{\text {st }}$ Jackal Symposium, Veliko Gradiste, Serbia (PPT).

Lim, Y. A. L.; Ngui, R.; Shukri, J.; Rohela, M. and Mat, N. H. R. (2008). Intestinal parasites in various animals at a zoo in Malaysia. Veterinary Parasitology, $157:$ 154-159.

Martinez-Moreno, F. J.; Hernandez, S.; Lopez-Cobos, E.; Becerra, C.; Acosta, I. and Martinez-Moreno, A. (2007). Estimation of canine intestinal parasites in CoRdoba (Spain) and their risk to public health. Veterinary Parasitology, $143: 7-13$.

Meshgi, B.; Eslami, A.; Bahonar, A. R.; Kharrazian, M. M. and Gerami, S. A. (2009). Prevalence of parasitic infections in the red fox (Vulpes vulpes) and golden jackal (Canis aureus) in Iran. Iranian Journal of Veterinary Research, Shiraz University, 10(4) : 29.

Mir, A. Q.; Dua, K.; Sigla, L. D.; Sharma, S. and Singh, M. P. (2016). Prevalence of parasitic infection in captive wild animals in Bir Moti Bagh mini zoo (Deer Park), Patiala, Punjab. Veterinary World, 9(6) : 540-543.

Polley, L. (2005). Navigating parasite webs and parasite flow : Emerging and re-emerging parasitic zoonosis of wildlife origin. International Journal of Parasitology, 35 : 1279-94.

Raja, M. M. R. U.; Dey, R. A.; Begum, N.; Kundu, K. U. and Ashad, A. F. (2014). Coprological prevalence of gastrointestinal parasites in carnivores and small mammals at Dhaka zoo. Bangladesh Journal of Threatened Taxa, 6(3): 5574-5579.

Rataj, V. A.; Posedi, J.; Zele, D. and Vengust, D. (2013). Intestinal parasites of the red fox (Vulpes vulpes) in Slovenia. Acta. Veterinaria Hungarica, $61: 454-462$.

Richards, D. T.; Harris, S. and Lewis, J. W. (1995). Epidemiological studies on intestinal helminth parasites of rural and urban red foxes (Vulpes vulpes) in the United Kingdom. Veterinary Parasitology, 59:39-51.

Roberts, L. and Janovy, J. J. R. (2000). Foundations of Parasitology. McGraw Hill, NewYork, p. 727.

Romero, C.; Mendoza, E. G.; Pineda, A. M.; Nava, N.; Bautista, G. L. and Heredia, R. (2015). Prevalence of Intestinal Parasites with Zoonotic Potential in Canids in Mexico city. Acta Scientiae Veterinariae, $43: 1307$.

Sarvi, S.; Daryani, A.; Sharif, M.; Rahimi, M. T.; Kohansal, M. H.; Mirshafiee, S.; Siyadatpanah, A.; Hosseini, S. and Gholami, S. (2018). Zoonotic intestinal parasites of carnivores : A systematic review in Iran. Veterinary World, 11(1) : 58-65.

Soulsby, E. J. L. (1982). Helminths, Arthropods and Protozoa of domesticated animals : $7^{\text {th }}$ edn. London, ELBS, p. 809.

Takacs, A.; Szabo, L.; Juhasz, L.; Takacs, A. A.; Lanszki, J.; Takacs, T. P. and Heltai, M. (2014). Data on the parasitological status of golden jackal (Canis aureus L., 1758) In Hungary. Acta. Veterinaria. Hungarica, 62(1) : 33-41.

Taylor, M. A.; Coop, R. L. and Wall, R. L. (2007). Veterinary parasitology: $3^{\text {rd }}$ edn. Blackwell Publishing, Oxford.

Thompson, R. C.; Lymberi, A. J. and Smith, A. (2010). Parasites, emerging disease and wildlife conservation. International Journal of Parasitology, $40: 1163-1170$.

Tompkins, D. M.; Carver, S.; Jones, M. E.; Krkosek, M. and Skerratt, L. F. (2015). Emerging infectious diseases of wildlife : A critical perspective. Trends in Parasitology, 31(4):149-59. 